\title{
Evolution and maintenance of sexual size dimorphism: aligning phylogenetic and experimental evidence
}

\author{
Matjaž Kuntner ${ }^{1,2,3 *}$ and Mark A. Elgar ${ }^{4}$ \\ 1 Institute of Biology, Scientific Research Centre of the Slovenian Academy of Sciences and Arts, Ljubljana, Slovenia \\ ${ }^{2}$ Centre for Behavioural Ecology and Evolution, College of Life Sciences, Hubei University, Wuhan, China \\ ${ }^{3}$ Department of Entomology, National Museum of Natural History, Smithsonian Institution, Washington, DC, USA \\ ${ }^{4}$ Department of Zoology, University of Melbourne, Melbourne, VIC, Australia
}

\section{Edited by:}

Patrick S. Fitze, University of

Lausanne, Switzerland

Reviewed by:

Tanja Schwander, University of Lausanne, Switzerland

Miquel Angel Arnedo, Universitat de

Barcelona, Spain

Adalberto José Dos Santos,

Universidade Federal de Minas

Gerais, Brazil

\section{*Correspondence:}

Matjaž Kuntner, Scientific Research Centre of the Slovenian Academy of Sciences and Arts, Novi trg 2, 1000 Ljubljana, Slovenia

e-mail:kuntner@gmail.com
Integrating the insights derived from both phylogenetic and experimental approaches offers a more complete understanding of evolutionary patterns and processes, yet it is rarely a feature of investigations of the evolutionary significance of trait variation. We combine these approaches to reinterpret the patterns and processes in the evolution of female biased sexual size dimorphism in Nephilidae, a spider lineage characterized by the most extreme sexual size dimorphism among terrestrial animals. We use a molecular phylogeny to reconstruct the size evolution for each sex and reveal a case of "sexually dimorphic gigantism": both sexes steadily outgrow their ancestral sizes, but the female and male slopes differ, and hence sexual size dimorphism steadily increases. A review of the experimental evidence reveals a predominant net selection for large size in both sexes, consistent with the phylogenetic pattern for females but not for males. Thus, while sexual size dimorphism in spiders most likely originates and is maintained by fecundity selection on females, it is unclear what selection pressures prevent males from becoming as large as females. This integrated approach highlights the dangers of inferring evolutionary significance from experimental studies that isolate the effects of single selection pressures.

Keywords: male-male competition, animal contests, female gigantism, male dwarfism, sexual cannibalism, Nephila spiders, Nephilidae

\section{INTRODUCTION}

Integrating insights from both phylogenetic and experimental approaches offers a more complete understanding of evolutionary patterns and processes, yet this is rarely a feature of investigations into the evolutionary significance of trait variation (Weber and Agrawal, 2012). The significance of this approach is that it reveals whether micro-evolutionary processes identified through field and laboratory experiments align with the macro-evolutionary patterns suggested by phylogenetic analyses (e.g., Arnqvist and Rowe, 2002). Such an approach requires broadly similar experiments to have been conducted across a range of species, for which there is also a robust phylogeny. Recent developments in systematics, together with the ease of sequencing, have significantly improved our capacity to integrate these approaches (Weber and Agrawal, 2012).

Sexual size dimorphism is particularly well suited to this kind of integrated analysis because measures of the trait are consistent between species and across experimental and comparative studies. The nature and direction of sexual size dimorphism reflects an intricate interplay of natural and sexual selection operating at various hierarchical levels (Darwin, 1871; Arak, 1988; Eberhard, 1996; Blanckenhorn, 2000, 2005; Fricke et al., 2010; Stillwell et al., 2010). Among invertebrates, for example, fecundity selection may favor large female size, while sexual selection through male-male competition may favor large male armaments that must be supported by larger body size. Natural selection might also act differently on each sex, placing upper or lower limits to body size. The resulting sexual size dimorphism will reflect differences in the strength of these selection components.

The spider family Nephilidae (Figure 1) has among the most extreme examples of sexual dimorphism (Elgar, 1991, 1992; Coddington et al., 1997; Kuntner et al., 2008); for example, female Nephila pilipes are on average 125 times heavier than males (Kuntner et al., 2012b). Such extreme female biased sexual size dimorphism has attracted numerous experimental and correlational studies to investigate the role of natural and sexual selection on size evolution in this clade (Kuntner et al., 2013). These studies have identified a number of potential fitness components influencing male and female body size, including fecundity, developmental rates, mate search, male-male competition, sperm competition, and sexual cannibalism (reviews in Elgar, 1992; Elgar and Schneider, 2004; Foellmer and Moya-Larano, 2007; Schneider and Fromhage, 2010; Schneider and Andrade, 2011). An earlier comparative study revealed no phylogenetic correlation between male and female size in nephilid spiders, with a steady evolution toward female gigantism but no clear trend for male size (Kuntner and Coddington, 2009). However, this study had several shortcomings: most notably, it derived from morphological 

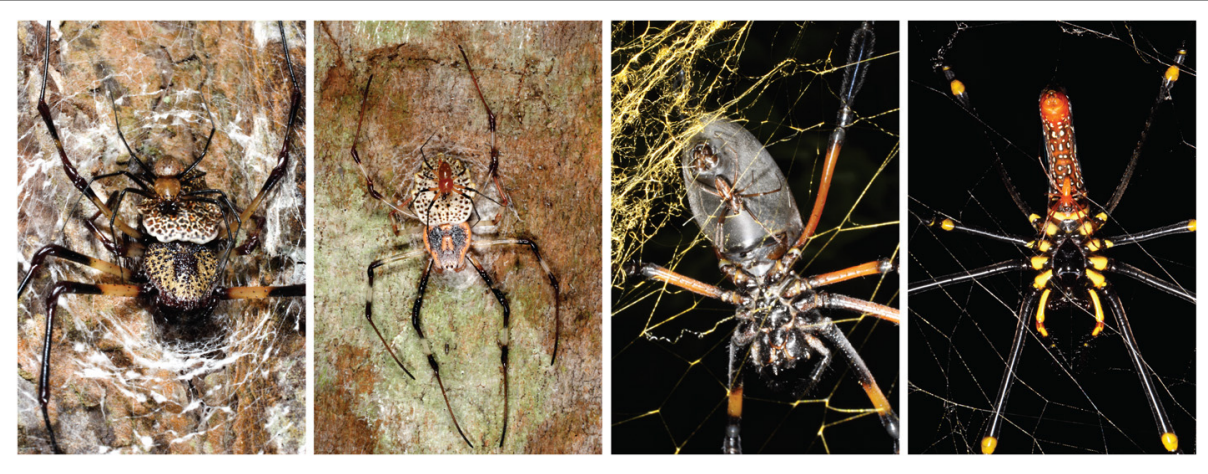

FIGURE 1 | Female biased sexual size dimorphism in nephilid spiders: From left to right, small males on females in $H$ Herennia etruscilla, $\boldsymbol{H}$. multipuncta, Nephila inaurata, and $N$. pilipes.

and behavioral character data (Kuntner et al., 2008) that lack a temporal perspective and branch length information, crucial for comparative tests (Garland et al., 2005). Further, sexual size dimorphism was one of the characters used for tree searches to create the phylogeny, so analyses of the evolutionary patterns of the trait are not independent of the underlying phylogeny.

We here review the nature and direction of selection pressures identified by experimental studies and compare these patterns against those revealed by contemporary phylogenetic analyses. In particular we use a new molecular, species level phylogeny of nephilid spiders that adds a time perspective and branch length information to a revised topology (Kuntner et al., 2013). Specifically, we test whether male and female size evolution is decoupled and whether the evolutionary trends of male and female size correspond with the selection pressures identified in the experimental studies.

\section{MATERIALS AND METHODS COMPARATIVE METHODS}

We use a recent, molecular nephilid phylogeny, inferred from over 4000 nucleotide characters, which proved robust in sensitivity analyses that also included total evidence (combined molecular and morphological datasets) (Kuntner et al., 2013). We pruned this reference phylogeny for most outgroup taxa, retaining only the "zygiellid" outgroup clade sister to nephilids, and for redundant ingroup taxa. We then updated the datasets on male and female size and sexual size dimorphism for novel evolutionary reconstructions and coevolutionary analyses (Felsenstein, 1985) on this tree.

The size data (Table S1) derive from Kuntner and Coddington (2009), but with additional data for Phonognatha graeffei (male mean $5.0 \mathrm{~mm}, n=5$; female mean $7.9 \mathrm{~mm}, n=10$ ) from Dondale (1966), for Zygiella x-notata from Hormiga et al. (2000), for Clitaetra thisbe male $(2.57 \mathrm{~mm}, n=1)$ from Dimitrov et al. (2009), for Herennia oz female $(11.6-13.6 \mathrm{~mm}, n=2)$ from Kuntner (2005), and for Nephilingis spp. (Kuntner and Agnarsson, 2011): N. livida female 15.5-23.6 mm $(n=10)$, male $3.1-4.9 \mathrm{~mm}(n=10), N$. borbonica: female $14.1-21.8 \mathrm{~mm}$ $(n=4), 3.8-6.1 \mathrm{~mm}(n=2), N$. dodo: female total length from 22.6-23.4 mm $(n=2)$, male total length from $4.6-6.6 \mathrm{~mm}$ $(n=3)$. Following Kuntner and Coddington (2009), sexual size dimorphism is expressed as the ratio of female to male average body size.

We explored coevolutionary patterns of continuous variables using phylogenetically independent contrasts (Felsenstein, 1985; Garland et al., 1992) in the PDAP module of Mesquite version 2.75 (Maddison and Maddison, 2012). The size data passed the PDAP test for data conformity, with the exception of male size correlating with its SD using one tailed $t$-value. We therefore used the inferred, untransformed branch lengths on the Bayesian nephilid baseline phylogeny (Kuntner et al., 2013) in combination with two tailed $t$-values. Character evolution reconstructions were visualized using squared change parsimony in Mesquite. Values optimized at nodes were assigned to cladogenetic events counting from the phylogenetic root (cladogenetic event $=0$ ) through internal nodes toward the terminal taxa in the phylogeny. The phylogeny postulated a total of 10 cladogenetic events (Figure 2; 0-9). These are taken to roughly represent a temporal scale for the size evolution, corresponding to an evolutionary history of 40-60 million years estimated for the family (Kuntner et al., 2013).

\section{EXPERIMENTAL STUDIES}

We searched for original papers investigating the impact of male and female body size variation on female fecundity, and male mate searching, courtship, and mating behavior of any nephilid taxon (Nephila and Nephilingis species) and relevant outgroups (Phonognatha).

\section{RESULTS AND DISCUSSION COMPARATIVE PATTERNS}

Male and female size changes were not phylogenetically correlated $\left[r^{2}=0.05, t=1.24, F_{(1,27)}=1.5,2\right.$-tailed $P=0.23$; Figure 2]. The lack of correlation implies that sexual size dimorphism in nephilids evolved as a response to selection pressures that differed between the sexes (Hormiga et al., 2000; Kuntner and Coddington, 2009). These results, however, do not reveal the direction of size change in each sex. The reconstruction of evolutionary changes in female and male size from all phylogenetic nodes (leading to all terminal taxa) showed a steady overall increase in female size $\left[r^{2}=0.155, \beta=1.35, F_{(1,51)}=9.39, P=\right.$ 0.004 ; Figure $3 \mathbf{A}]$, and a slight increase in male size over time 

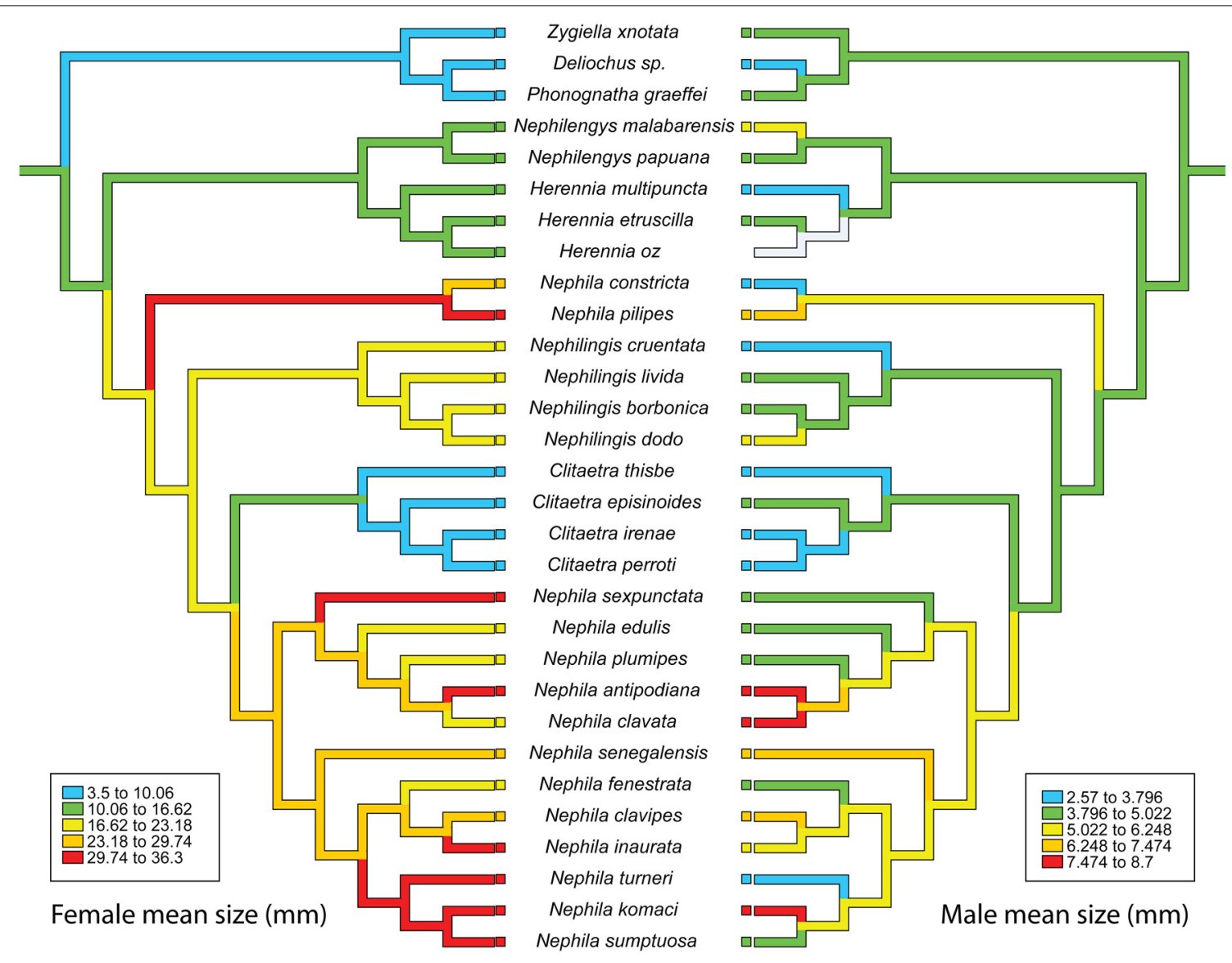

FIGURE 2 | Reconstructed evolution of female (left) and male (right) mean sizes in nephilid spiders. The lack of correlation implies that sexual size dimorphism evolves as a response of different selection pressures on females and males.

$\left[r^{2}=0.191, \beta=0.233, F_{(1,41)}=11.58, P=0.001\right.$; Figure 3A $]$. These slopes are significantly different [ANCOVA: sex by cladogenetic event, $\left.F_{(1,100)}=6.09, P=0.015\right]$. The evolutionary result is a trend toward overall increase of sexual size dimorphism over time (Figure 3B). Since parts of the phylogeny may conceivably exhibit different trends in size evolution, we also reconstructed the evolution of female and male size on a selected cladogenetic route leading to extreme female gigantism, that is on a phylogenetic backbone leading from the nephilid root to Nephila komaci, the largest known nephilid (Kuntner and Coddington, 2009). This reconstruction showed that over evolutionary time, there was a strong steady increase in female size $\left[r^{2}=0.943, \beta=2.351\right.$, $F_{(1,9)}=133.05, P<0.001$; Figure 3C] and a less pronounced increase in male size $\left[r^{2}=0.656, \beta=0.344, F_{(1,9)}=15.24\right.$, $P=0.005$; Figure 3C]. Again, these slopes are significantly different [ANCOVA: sex by cladogenetic event, $F_{(1,16)}=81.74$, $P<0.001]$. From the root to the tip of the giant Nephila clade, sexual size dimorphism shows a significant evolutionary increase $\left[r^{2}=0.466, \beta=0.218, F_{(1,9)}=6.973, P=0.03\right.$; Figure 3D $]$.

\section{EXPERIMENTAL EVIDENCE}

Experimental and observational studies on Nephila suggest that selection should generally favor larger than ancestral size for both sexes (Table 1). However, there is little consistency in these patterns across different Nephila species. Contrary to conventional wisdom, evidence for fecundity selection is demonstrated in only three of six species, despite the phylogenetic evidence for strong selection on female size. Intriguingly, the phylogenetic analysis reveals an evolutionary decline in size in the three species (N. edulis, N. plumipes and N. fenestrata) for which there is no evidence of fecundity selection, and either no change $(N$. clavipes, $N$. senegalensis) or an increase ( $N$. pilipes) in size in those species for which there is evidence of fecundity selection. It would be worth testing this trend in other nephilids for which we lack any evidence for the strength of fecundity selection. For example, one would predict strong fecundity selection in those species that have made the most contribution to the general increase in female size (Figure 2): N. sexpunctata, $N$. antipodiana, $N$. inaurata, and the clade with African giants $(N$. turneri, N. komaci, N. sumptuosa). On the other hand, we predict relaxed fecundity selection in species/clades that show female size decrease (Figure 2): N. clavata, N. constricta, and in Clitaetra species.

The evidence for males is even more equivocal: five of six species show a large size advantage in male-male competition, but whether this translates into greater paternity is unclear because 

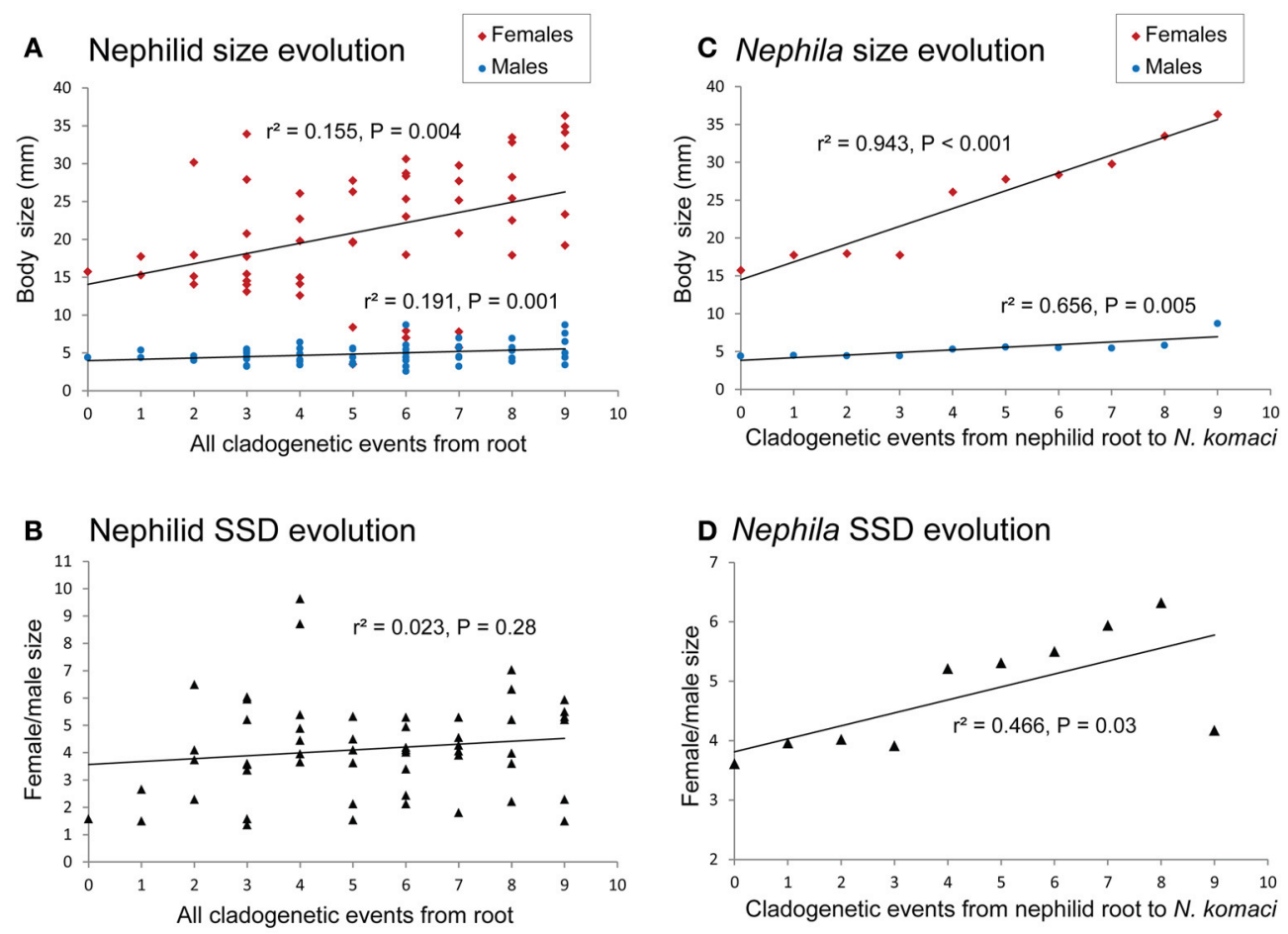

FIGURE 3 | Reconstructed evolutionary changes in female and male size and sexual size dimorphism. The phylogeny postulates 10 cladogenetic events (on $x$ axis) that together correspond to an evolutionary history of 40-60 million years estimated for the family (Kuntner et al., 2013). Nephilid size evolution (A) takes all phylogenetic nodes leading to all terminal taxa across the nephilid phylogeny

resulting in a non-significant overall increase of sexual size dimorphism over time (B). Size evolution reconstructed from the nephilid root to the largest known nephilid, Nephila komaci shows a strong steady increase in female size and a slight increase in male size over cladogenetic time (C) resulting in a significant evolutionary increase of sexual size dimorphism (D).

two of four studies reveal an advantage of small size under sperm competition. Further, experimental studies in which both preand post-insemination selection pressures can act together over a longer time revealed no comparative advantage for small or large males (Schneider and Elgar, 2005; Elgar and Jones, 2008). Finally, only one of two studies that investigated mate search revealed a large size advantage, and studies of two species indicated that large males were more likely to avoid sexual cannibalism.

\section{SYNTHESIS}

The conventional phylogenetic view of the origin of female biased sexual size dimorphism in spiders is through an evolutionary increase in female size, an evolutionary decrease in male size, or both (Coddington et al., 1997; Hormiga et al., 2000). Our phylogenetic analysis reveals an increase in the size of both female and male nephilids. This result, together with the evidence from experimental studies, does not support the view that sexual size dimorphism in this clade is an outcome of male dwarfing (Vollrath, 1998; Danielson-Francois et al., 2012). Rather, it reflects a pattern of sexually decoupled size evolution (Kuntner and Coddington, 2009), not through male evolutionary stasis (Hormiga et al., 2000; Kuntner and Coddington, 2009), but with male and female body size increasing at different rates. This new macro-evolutionary pattern may be described as sexually dimorphic gigantism.
The disparity between the macro-evolutionary patterns, revealed by our phylogenetic analysis, and the micro-evolutionary processes identified by experimental studies is instructive. For example, the large size advantage in competitive interactions between males identified in five of six species of Nephila is consistent with numerous studies of taxonomically diverse species that are not characterized by extreme sexual size dimorphism (Hardy and Briffa, 2013). But the Nephila data simply do not align with either the natural history of this clade (extreme sexual size dimorphism), or the macro-evolutionary patterns (a significantly more modest increase in male size compared with female size). Perhaps these experimental results are evolutionarily trivial because they focus on single components of selection that have little impact on macro-evolutionary processes. Indeed, experiments that combined pre- and post- insemination selection pressures revealed no relationship between male size and paternity share (Schneider and Elgar, 2005; Elgar and Jones, 2008).

Our understanding of sexual size dimorphism has converged on the equilibrium model (Blanckenhorn, 2000), suggesting that a combination of selection pressures is expected to operate on spider males (Foellmer and Moya-Larano, 2007). Combined, they must push male size down, hence the detected genetic decoupling of male and female size evolution in nephilid spiders. If the sizes were genetically linked in both sexes, as is the default in animals (spiders not being an exception, see Uhl et al., 2004), the slopes 


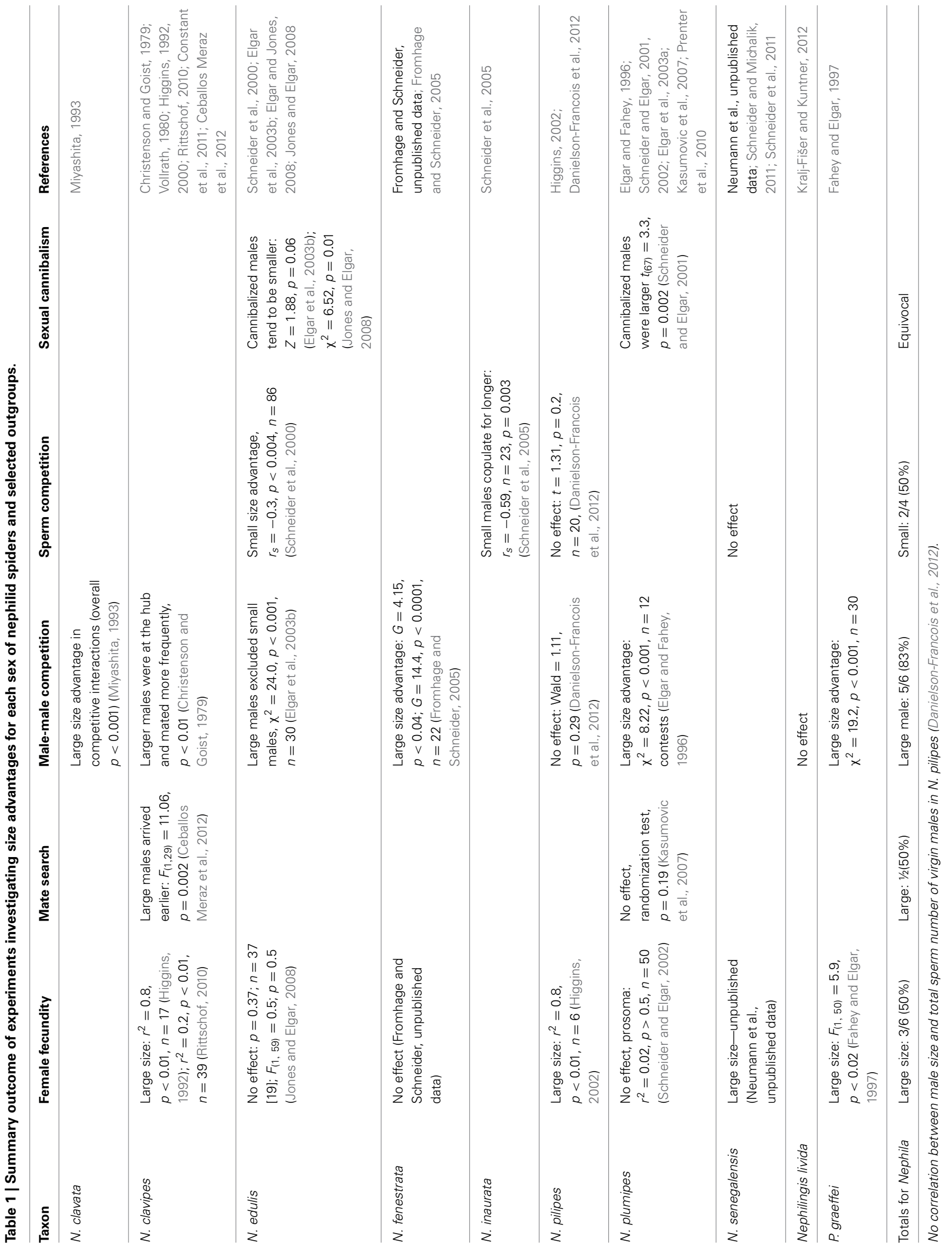


would not significantly differ and the independent contrasts test would not show independence, as observed here. The question future studies should be posing, then, is what maintains small male size and thus high sexual size dimorphism? In other words, in spite of the macro-evolutionary trends to increase in size, why are the males not giants, as are the females? Extreme sexual size dimorphism is not typical of species of orb-weaving spiders with large females: there is modest sexual size dimorphism in the orbweaver genus Eriophora, in which adult females are of similar size to Nephila (Elgar, 1991). Thus, future experimental studies might profitably focus on selection pressures that could disfavor large male body size, including those that may arise through conflict with female interests, dispersal between webs and long-term survival.

Several authors have suggested that small male size is favored in response to sexual cannibalism (Elgar, 1991), protandry (Danielson-Francois et al., 2012; Elwood and Prenter, 2013), or gravity (Moya-Larano et al., 2002, 2009; Corcobado et al., 2010), but these ideas have attracted either little attention or no empirical support (Table 1; see also Prenter et al., 2010). Perhaps the low variance in male mating success that frequently characterizes the mating system of these spiders limits the opportunity for selection on male size. In many nephilid species, male genitalia are damaged during mating, leaving the male incapable of further mating and his broken remnants acting as a total or partial mating plug (Kuntner et al., 2009, 2012a). The exceptions may provide insights: both males and females of $N$. edulis mate multiply, and single interaction experimental studies reveal both large (Elgar et al., 2003b) and small (Schneider et al., 2000) male size advantages that are counter-balanced over the longer term (Schneider and Elgar, 2005; Elgar and Jones, 2008). Sexual dimorphism is extremely variable in this species, with some males roughly an order of magnitude larger than other males (Elgar et al., 2003b). Perhaps multiple mating by both sexes in this species provides a greater opportunity for selection to act on male size variation. Intriguingly, $N$. senegalensis, $N$. inaurata and $N$. clavipes have similar variation in male size (Higgins et al., 2011), and it would be interesting to investigate the impact of male size on male mating success over the longer term (following Elgar and Jones, 2008) in these species.

\section{OUTLOOK}

Our study highlights the benefits of integrating insights derived from phylogenetic, comparative and experimental research. Like many studies of phenotypic traits, investigations into the evolutionary significance of sexual size dimorphism in spiders have utilized two methodological approaches, one phylogenetic, the other experimental, with each progressing largely independently. In isolation, phylogenetic and comparative analyses only reveal macro-evolutionary patterns of phenotypic evolution, while experimental studies only highlight population level processes responsible for trait maintenance. Such an insight is not new (Coddington, 1988, 1990), but our capacity to align these approaches is only recently becoming possible (Weber and Agrawal, 2012). For fully integrative studies, experimental and comparative agendas need to define common goals and priorities. Our survey showed that for investigations of sexual size dimorphism in orb-web spiders, comparative data remain insufficient; experimental work suffers from a lack of selection differentials; and we need far greater taxonomic coverage than selective studies on a handful of model species (see also Zuk et al., 2014).

Despite these shortcomings, the present study shows how a more complex picture of sexual size dimorphism emerges when phylogenetic and experimental evidence are integrated. Selection favors large size in both males and females, but fecundity selection is stronger than the net selection for large male size (Blanckenhorn, 2000; Stillwell et al., 2010). At the scale of 40-60 million years of evolution (Kuntner et al., 2013), the size increases-genetically uncoupled between the sexes-result in a peculiar case of sexually dimorphic gigantism. New phylogenetic and experimental evidence will likely provide useful insights, but integrating these approaches is crucial.

\section{ACKNOWLEDGMENTS}

We thank I. Agnarsson, M. Arnedo, R.-C. Cheng, J. Coddington, M. Gregorič, L. Higgins, T. Jones, S. Kralj-Fišer, D. Li, and J. Schneider for numerous discussions and/or data sharing. Matjaž Kuntner was supported by the Slovenian Research Agency (grant P1-10236), and Mark A. Elgar by the Australian Research Council (grant DP0209680).

\section{SUPPLEMENTARY MATERIAL}

The Supplementary Material for this article can be found online at: http://www.frontiersin.org/journal/10.3389/fevo.2014.00026/ abstract

\section{REFERENCES}

Arak, A. (1988). Sexual dimorphism in body size - a model and a test. Evolution 42, 820-825. doi: $10.2307 / 2408874$

Arnqvist, G., and Rowe, L. (2002). Antagonistic coevolution between the sexes in a group of insects. Nature 415, 787-789. doi: 10.1038/415787a

Blanckenhorn, W. U. (2000). The evolution of body size: what keeps organisms small? Q. Rev. Biol. 75, 385-407. doi: 10.1086/393620

Blanckenhorn, W. U. (2005). Behavioral causes and consequences of sexual size dimorphism. Ethology 111, 977-1016. doi: 10.1111/j.1439-0310.2005. 01147.x

Ceballos Meraz, L., Henaut, Y., and Elgar, M. A. (2012). Effects of male size and female dispersion on male mate-locating success in Nephila clavipes. J. Ethol. 30, 93-100. doi: 10.1007/s10164-011-0300-2

Christenson, T. E., and Goist, K. C. (1979). Costs and benefits of male-male competition in the orb weaving spider, Nephila clavipes. Behav. Ecol. Sociobiol. 5, 87-92. doi: 10.1007/BF00302697

Coddington, J. A. (1988). Cladistic tests of adaptational hypotheses. Cladistics 4, 3-22. doi: 10.1111/j.1096-0031.1988.tb00465.x

Coddington, J. A. (1990). Bridges between evolutionary pattern and process. Cladistics 6, 379-386. doi: 10.1111/j.1096-0031.1990.tb00553.x

Coddington, J. A., Hormiga, G., and Scharff, N. (1997). Giant female or dwarf male spiders? Nature 385, 687-688. doi: 10.1038/385687a0

Constant, N., Valbuena, D., and Rittschof, C. C. (2011). Male contest investment changes with male body size but not female quality in the spider Nephila clavipes. Behav. Process. 87, 218-223. doi: 10.1016/j.beproc.2011. 04.003

Corcobado, G., Rodriguez-Girones, M. A., De Mas, E., and Moya-Larano, J. (2010). Introducing the refined gravity hypothesis of extreme sexual size dimorphism. BMC Evol. Biol. 10:236. doi: 10.1186/1471-2148-10-236

Danielson-Francois, A., Hou, C., Cole, N., and Tso, I. M. (2012). Scramble competition for moulting females as a driving force for extreme male dwarfism in spiders. Anim. Behav. 84, 937-945. doi: 10.1016/j.anbehav.2012.07.018

Darwin, C. (1871). The Descent of Man, and Selection in Relation to Sex. London: John Murray. doi: 10.1037/12293-000 
Dimitrov, D., Benjamin, S. P., and Hormiga, G. (2009). A revised phylogenetic analysis for the spider genus Clitaetra Simon, 1889 (Araneae, Araneoidea, Nephilidae) with the first description of the male of the Sri Lankan species Clitaetra thisbe Simon, 1903. Bull. Mus. Comp. Zool. 159, 301-323. doi: 10.3099/0027-4100-159.6.301

Dondale, C. D. (1966). The spider fauna (Araneida) of deciduous orchards in the Australian Capital Territory. Aust. J. Zool. 14, 1157-1192. doi: 10.1071/ZO9661157

Eberhard, W. G. (1996). Female Control: Sexual Selection By Cryptic Female Choice. Princeton; Oxford: Princeton University Press.

Elgar, M. A. (1992). "Sexual cannibalism in spiders and other invertebrates," in Cannibalism: Ecology and Evolution Among Diverse Taxa, eds M. A. Elgar and B. E. Crespi (Oxford; New York, NY: Oxford University Press), 129-156.

Elgar, M. A. (1991). Sexual cannibalism, size dimorphism, and courtship behavior in orb-weaving spiders (Araneidae). Evolution 45, 444-448. doi: $10.2307 / 2409679$

Elgar, M. A., Bruce, M. J., and De Crespigny, F. E. C. (2003a). Male mate choice and patterns of paternity in the polyandrous, sexually cannibalistic orb-web spider Nephila plumipes. Aust. J. Zool. 51, 357-365. doi: 10.1071/ZO02079

Elgar, M. A., De Crespigny, F. E. C., and Ramamurthy, S. (2003b). Male copulation behaviour and the risk of sperm competition. Anim. Behav. 66, 211-216. doi: 10.1006/anbe.2003.2189

Elgar, M. A., and Fahey, B. F. (1996). Sexual cannibalism, competition, and size dimorphism in the orb-weaving spider Nephila plumipes Latreille (Araneae: Araneoidea). Behav. Ecol. 7, 195-198. doi: 10.1093/beheco/7.2.195

Elgar, M. A., and Jones, T. M. (2008). Size-dependent mating strategies and the risk of cannibalism. Biol. J. Linnean Soc. 94, 355-363. doi: 10.1111/j.10958312.2008.00986.x

Elgar, M. A., and Schneider, J. M. (2004). Evolutionary significance of sexual cannibalism. Adv. Stud. Behav. 34, 135-163. doi: 10.1016/S0065-3454(04)34004-0

Elwood, R., and Prenter, J. (2013). "Aggression in spiders," in Animal Contests, eds I. Hardy and M. Briffa (Cambridge: Cambridge University Press), 113-133. doi: 10.1017/CBO9781139051248.008

Fahey, B. F., and Elgar, M. A. (1997). Sexual cohabitation as mate-guarding in the leaf-curling spider Phonognatha graeffei Keyserling (Araneoidea, Araneae). Behav. Ecol. Sociobiol. 40, 127-133. doi: 10.1007/s002650050325

Felsenstein, J. (1985). Phylogenies and the comparative method. Am. Nat. 125, 1-15. doi: 10.1086/284325

Foellmer, M. W., and Moya-Larano, J. (2007). "Sexual size dimorphism in spiders: patterns and processes," in Sex, Size, and Gender Roles: Evolutionary Studies of Sexual Size Dimorphism, eds D. J. Fairbairn, W. U. Blanckenhorn, and T. Szekely (New York, NY: Oxford University Press), 71-81.

Fricke, C., Andersson, C., and Arnqvist, G. (2010). Natural selection hampers divergence of reproductive traits in a seed beetle. J. Evol. Biol. 23, 1857-1867. doi: 10.1111/j.1420-9101.2010.02050.x

Fromhage, L., and Schneider, J. M. (2005). Virgin doves and mated hawks: contest behaviour in a spider. Anim. Behav. 70, 1099-1104. doi: 10.1016/j.anbehav.2005.02.020

Garland, T., Bennett, A. F., and Rezende, E. L. (2005). Phylogenetic approaches in comparative physiology. J. Exp. Biol. 208, 3015-3035. doi: 10.1242/jeb.01745

Garland, T., Harvey, P. H., and Ives, A. R. (1992). Procedures for the analysis of comparative data using phylogenetically independent contrasts. Syst. Biol. 41, 18-32. doi: 10.1093/sysbio/41.1.18

Hardy, I., and Briffa, M. (2013). Animal Contests. Cambridge: Cambridge University Press. doi: 10.1017/CBO9781139051248

Higgins, L. (2000). The interaction of season length and development time alters size at maturity. Oecologia 122, 51-59. doi: 10.1007/PL00008835

Higgins, L. (2002). Female gigantism in a New Guinea population of the spider Nephila maculata. Oikos 99, 377-385. doi: 10.1034/j.1600-0706.2002. 990220.x

Higgins, L., Coddington, J., Goodnight, C., and Kuntner, M. (2011). Testing ecological and developmental hypotheses of mean and variation in adult size in nephilid orb-weaving spiders. Evol. Ecol. 25, 1289-1306. doi: 10.1007/s10682011-9475-9

Higgins, L. E. (1992). Developmental plasticity and fecundity in the orb-weaving spider Nephila clavipes. J. Arachnol. 20, 94-106.

Hormiga, G., Scharff, N., and Coddington, J. A. (2000). The phylogenetic basis of sexual size dimorphism in orb-weaving spiders (Araneae, Orbiculariae). Syst. Biol. 49, 435-462. doi: 10.1080/10635159950127330
Jones, T. M., and Elgar, M. A. (2008). Male insemination decisions and sperm quality influence paternity in the golden orb-weaving spider. Behav. Ecol. 19, 285-291. doi: 10.1093/beheco/arm126

Kasumovic, M. M., Bruce, M. J., Herberstein, M. E., and Andrade, M. C. B. (2007) Risky mate search and mate preference in the golden orb-web spider (Nephila plumipes). Behav. Ecol. 18, 189-195. doi: 10.1093/beheco/arl072

Kralj-Fišer, S., and Kuntner, M. (2012). Eunuchs as better fighters? Naturwissenschaften 99, 95-101. doi: 10.1007/s00114-011-0873-1

Kuntner, M. (2005). A revision of Herennia (Araneae: Nephilidae: Nephilinae), the Australasian 'coin spiders.' Invert. Syst. 19, 391-436. doi: 10.1071/IS05024

Kuntner, M., and Agnarsson, I. (2011). Biogeography and diversification of hermit spiders on Indian Ocean islands (Nephilidae: Nephilengys). Mol. Phylogenet. Evol. 59, 477-488. doi: 10.1016/j.ympev.2011.02.002

Kuntner, M., Arnedo, M. A., Trontelj, P., Lokovšek, T., and Agnarsson, I. (2013). A molecular phylogeny of nephilid spiders: Evolutionary history of a model lineage. Mol. Phylogenet. Evol. 69, 961-979. doi: 10.1016/j.ympev.2013.06.008

Kuntner, M., and Coddington, J. A. (2009). Discovery of the largest orbweaving spider species: the evolution of gigantism in Nephila. PLoS ONE 4:e7516. doi: 10.1371/journal.pone.0007516

Kuntner, M., Coddington, J. A., and Hormiga, G. (2008). Phylogeny of extant nephilid orb-weaving spiders (Araneae, Nephilidae): testing morphological and ethological homologies. Cladistics 24, 147-217. doi: 10.1111/j.10960031.2007.00176.x

Kuntner, M., Coddington, J. A., and Schneider, J. M. (2009). Intersexual arms race? Genital coevolution in nephilid spiders (Araneae, Nephilidae). Evolution 63, 1451-1463. doi: 10.1111/j.1558-5646.2009.00634.x

Kuntner, M., Gregorič, M., Zhang, S., Kralj-Fišer, S., and Li, D. (2012a). Mating plugs in polyandrous giants: which sex produces them, when, how and why? PLoS ONE 7:e40939. doi: 10.1371/journal.pone.0040939

Kuntner, M., Zhang, S., Gregorič, M., and Li, D. (2012b). Nephila female gigantism attained through post-maturity molting. J. Arachnol. 40, 344-346. doi: 10.1636/B12-03.1

Maddison, W. P., and Maddison, D. R. (2012). Mesquite: A Modular System For Evolutionary Analysis, 2.5 ed. Available online at: http://mesquiteproject.org

Miyashita, T. (1993). Male male competition and mating success in the orb-web spider, Nephila clavata, with reference to temporal factors. Ecol. Res. 8, 93-102. doi: $10.1007 / \mathrm{BF} 02348612$

Moya-Larano, J., Halaj, J., and Wise, D. H. (2002). Climbing to reach females: Romeo should be small. Evolution 56, 420-425. doi: 10.1111/j.00143820.2002.tb01351.x

Moya-Larano, J., Vinkovic, D., Allard, C. M., and Foellmer, M. W. (2009). Optimal climbing speed explains the evolution of extreme sexual size dimorphism in spiders. J. Evol. Biol. 22, 954-963. doi: 10.1111/j.1420-9101.2009.01707.x

Prenter, J., Perez-Staples, D., and Taylor, P. W. (2010). The effects of morphology and substrate diameter on climbing and locomotor performance in male spiders. Funct. Ecol. 24, 400-408. doi: 10.1111/j.1365-2435.2009.01633.x

Rittschof, C. C. (2010). Male density affects large-male advantage in the golden silk spider, Nephila clavipes. Behav. Ecol. 21, 979-985. doi: 10.1093/beheco/arq099

Schneider, J., and Andrade, M. C. B. (2011). "Mating behaviour and sexual selection," in Spider Behaviour: Flexibility and Versatility, ed M. E. Herberstein (Cambridge: Cambridge University Press), 215-274. doi: 10.1017/CBO9780511974496.008

Schneider, J., and Fromhage, L. (2010). "Monogynous mating strategies in spiders," in Animal Behaviour: Evolution and Mechanisms, ed P. Kapela (Berlin; Heidelberg: Springer), 441-464. doi: 10.1007/978-3-642-02624-9_15

Schneider, J. M., and Elgar, M. A. (2001). Sexual cannibalism and sperm competition in the golden orb-web spider Nephila plumipes (Araneoidea): female and male perspectives. Behav. Ecol. 12, 547-552. doi: 10.1093/beheco/12.5.547

Schneider, J. M., and Elgar, M. A. (2002). Sexual cannibalism in Nephila plumipes as a consequence of female life history strategies. J. Evol. Biol. 15, 84-91. doi: 10.1046/j.1420-9101.2002.00363.x

Schneider, J. M., and Elgar, M. A. (2005). The combined effects of pre- and postinsemination sexual selection on extreme variation in male body size. Evol. Ecol. 19, 419-433. doi: 10.1007/s10682-005-8310-6

Schneider, J. M., Fromhage, L., and Uhl, G. (2005). Copulation patterns in the golden orb-web spider Nephila madagascariensis. J. Ethol. 23, 51-55. doi: 10.1007/s10164-004-0128-0

Schneider, J. M., Herberstein, M. E., De Crespigny, F. C., Ramamurthy, S., and Elgar, M. A. (2000). Sperm competition and small size advantage for males 
of the golden orb-web spider Nephila edulis. J. Evol. Biol. 13, 939-946. doi: 10.1046/j.1420-9101.2000.00238.x

Schneider, J. M., Lucass, C., Brandler, W., and Fromhage, L. (2011). Spider males adjust mate choice but not sperm allocation to cues of a rival. Ethology 117, 970-978. doi: 10.1111/j.1439-0310.2011.01960.x

Schneider, J. M., and Michalik, P. (2011). One-shot genitalia are not an evolutionary dead end - Regained male polygamy in a sperm limited spider species. $B M C$ Evol. Biol. 11:197. doi: 10.1186/1471-2148-11-197

Stillwell, R. C., Blanckenhorn, W. U., Teder, T., Davidowitz, G., and Fox, C. W. (2010). Sex differences in phenotypic plasticity affect variation in sexual size dimorphism in insects: from physiology to evolution. Annu. Rev. Entomol. 55, 227-245. doi: 10.1146/annurev-ento-112408-085500

Uhl, G., Schmitt, S., Schafer, M. A., and Blanckenhorn, W. (2004). Food and sexspecific growth strategies in a spider. Evol. Ecol. Res. 6, 523-540.

Vollrath, F. (1980). Male body size and fitness in the web-building spider Nephila clavipes. Zeitschrift Tierpsychologie J. Comp. Ethol. 53, 61-78.

Vollrath, F. (1998). Dwarf males. Trends Ecol. Evol. 13, 159-163. doi: 10.1016/S01695347(97)01283-4

Weber, M. G., and Agrawal, A. A. (2012). Phylogeny, ecology, and the coupling of comparative and experimental approaches. Trends Ecol. Evol. 27, 394-403. doi: 10.1016/j.tree.2012.04.010
Zuk, M., Garcia-Gonzalez, F., Herberstein, M., and Simmons, L. (2014). Model systems, taxonomic bias, and sexual selection: beyond Drosophila. Аnnu. Rev. Entomol. 59, 321-338. doi: 10.1146/annurev-ento-011613162014

Conflict of Interest Statement: The authors declare that the research was conducted in the absence of any commercial or financial relationships that could be construed as a potential conflict of interest.

Received: 14 February 2014; accepted: 31 May 2014; published online: 18 June 2014. Citation: Kuntner M and Elgar MA (2014) Evolution and maintenance of sexual size dimorphism: aligning phylogenetic and experimental evidence. Front. Ecol. Evol. 2:26. doi: $10.3389 /$ fevo.2014.00026

This article was submitted to Behavioral and Evolutionary Ecology, a section of the journal Frontiers in Ecology and Evolution.

Copyright $\odot 2014$ Kuntner and Elgar. This is an open-access article distributed under the terms of the Creative Commons Attribution License (CC BY). The use, distribution or reproduction in other forums is permitted, provided the original author(s) or licensor are credited and that the original publication in this journal is cited, in accordance with accepted academic practice. No use, distribution or reproduction is permitted which does not comply with these terms. 